\title{
Unilateral Thyroid-Associated Orbitopathy as the Only Sign of Occult Celiac Disease: Effective Treatment with a Gluten-Free Diet
}

\author{
Ilaria Stramazzo ${ }^{1,2}$, Marco Centanni ${ }^{1,2}$, Camilla Virili $^{1}$ \\ ${ }^{1}$ Department of Medico-Surgical Sciences and Biotechnologies, Sapienza University of Rome; ${ }^{2}$ Endocrine Unit, AUSL Latina, \\ Latina, Italy
}

\begin{abstract}
A 36-year-old Caucasian woman presented to our clinic with unilateral orbitopathy. In the previous 3 months, she had noticed that her right eye was "more opened" with irritation, burning, increased tearing, and episodic retrobulbar pain. Her past medical history included only a diagnosis of euthyroid Hashimoto thyroiditis (HT) 13 years before. Examining her previous clinical reports, we detected positivity for anti-transglutaminase antibodies (anti-tTg Ab), which dated back to the time of the diagnosis of HT and had not been further investigated. Since then, she reported a varied diet, regular menstruation, and normal bowel movements. She reported no history of pregnancy, abortions, smoking habit, or allergies. Her only medication was a history of contraceptive pill use for several years.
\end{abstract}

Thyroid ultrasonography showed the typical features of chronic autoimmune thyroiditis, while blood tests confirmed a normal thyroid-stimulating hormone (TSH) level (3.5 mU/L), along with strong positivity for anti-thyroglobulin and anti-thyroperoxidase antibodies (anti-Tg Ab and anti-TPO Ab).

A whole-eye examination demonstrated, in the right eye, mild eyelid swelling, mild redness of the conjunctiva, and upper eyelid retraction (eyelid aperture $12 \mathrm{~mm}$ vs. $9 \mathrm{~mm}$ in the left eye). No sign of orbitopathy was found in the left eye. There was no proptosis (both eyes $18 \mathrm{~mm}$ ), and visual acuity was normal in the absence of diplopia. On a physical examination, anthropo-

Received: 2 February 2021, Accepted: 5 April 2021

Corresponding author: Camilla Virili

Department of Medico-Surgical Sciences and Biotechnologies, Sapienza

University of Rome, Corso della Repubblica 79, Latina, Italy

Tel: +39-06-49972604, Fax: +39-06-49972604,

E-mail: camilla.virili@uniroma1.it metric parameters were normal (weight $55 \mathrm{~kg}$, height $162 \mathrm{~cm}$, body mass index $21 \mathrm{~kg} / \mathrm{m}^{2}$ ), and the patient's vital signs were also in the normal range. The thyroid was palpable with an increased texture, in the absence of signs of hyperfunction or hypofunction. As expected, anti-TSH receptor antibodies (TRAb) were positive (2.8 times above the upper limit). Orbital magnetic resonance imaging showed mild dacryoadenitis and thickening of the levator palpebrae muscle, restricted to the right orbit. We assessed the patient's orbitopathy as active according to the Clinical Activity Score (3 points) and mild according to the European Group of Graves' Orbitopathy classification.

Because of the finding of anti-tTg Ab positivity, which had been neglected 13 years before, and the described association between thyroid autoimmunity and celiac disease (CD), we decided to further investigate this possibility, and again obtained an increased concentration of these autoantibodies. Duodenal endoscopy was thus performed, revealing increased intraepithelial lymphocytes, hyperplastic crypts, and severe villous atrophy (Marsh 3c CD). We then confirmed the diagnosis of unilateral and euthyroid thyroid-associated orbitopathy (TAO) in a patient with $\mathrm{CD}$. Therefore, the patient was advised to start a gluten-free diet (GFD) and she agreed. The patient then noticed a progressive improvement of ocular signs and symptoms. Three months later, a blood test revealed that serum TRAb and anti-tTgAb had

Copyright $\odot 2021$ Korean Endocrine Society

This is an Open Access article distributed under the terms of the Creative Commons Attribution Non-Commercial License (https://creativecommons.org/ licenses/by-nc/4.0/) which permits unrestricted non-commercial use, distribution, and reproduction in any medium, provided the original work is properly cited. 
Table 1. Changes in the Patient's Biochemical and Clinical Features over Time

\begin{tabular}{|c|c|c|c|c|}
\hline & $\begin{array}{l}\text { Diagnosis of HT } \\
(23 \mathrm{yr})\end{array}$ & $\begin{array}{l}\text { Onset of orbitopathy } \\
\text { (36 yr) }\end{array}$ & $\begin{array}{c}3 \text { Months after starting } \\
\text { GFD }\end{array}$ & $\begin{array}{c}6 \text { Months after starting } \\
\text { GFD }\end{array}$ \\
\hline TSH, mIU/L (normal range, 0.35-4.94) & 0.52 & 3.5 & 3.98 & 3.45 \\
\hline FT4, ng/dL (normal range, 0.7-1.48) & 0.9 & 0.8 & 1 & 1.2 \\
\hline $\mathrm{TG} A \mathrm{Ab}, \mathrm{IU} / \mathrm{mL}(<100)$ & 774 & 756 & 1.533 & - \\
\hline TPO Ab, IU/mL $(<16)$ & 461 & 549 & 651 & - \\
\hline TRAb, IU/L $(<1.2)$ & - & 3.4 & $<1.2$ & $<1.2$ \\
\hline tTG Ab IgA, IU/mL $(<16)$ & 31 & 25 & $<16$ & $<16$ \\
\hline Eyelid aperture (right eye), $\mathrm{mm}$ & - & 12 & - & 10 \\
\hline
\end{tabular}

HT, Hashimoto thyroiditis; GFD, gluten-free diet; TSH, thyroid-stimulating hormone; FT4, free thyroxine; TG Ab, anti-thyroglobulin antibody; TPO Ab, anti-thyroperoxidase antibody; TRAb, anti-TSH receptor antibody; tTG Ab IgA, anti-transglutaminase immunoglobulin A antibody.

disappeared, while the TSH concentration $(3.98 \mathrm{mU} / \mathrm{L})$ was unchanged and anti-Tg and anti-TPO positivity persisted. An eye examination 6 months later demonstrated the disappearance of soft tissue signs and improvement of upper eyelid retraction (eyelid aperture $10 \mathrm{~mm}$ ) (Table 1).

$\mathrm{CD}$ is now recognized as being symptomless (occult $\mathrm{CD}$ ) in many cases, but almost half of all patients with $\mathrm{CD}$ present extraintestinal manifestations, including some ophthalmic disorders (e.g., nyctalopia, TAO, and uveitis) [1]. Of note, transglutaminase, the gluten catabolic enzyme, has been described in thyroid tissue and the binding of anti-tTGAb may trigger inflammation and thyroid dysfunction [2]. In patients with thyroid autoimmunity, there is a fourfold increased risk for TAO in patients with concomitant CD [3]. Euthyroid/hypothyroid TAO represents $0.2 \%$ to $11 \%$ of all cases of TAO [4] and shows less severe, less active, and more asymmetrical orbitopathy than is observed in hyperthyroid TAO patients [5]. The unilateral form, showing one or more features of orbitopathy in one eye, occurs in $5 \%$ to $15 \%$ of all cases of TAO and its pathogenesis is poorly understood [4].

While some cases of improved uveitis in CD patients following a GFD have been described [1], this report, to the best of our knowledge, is the first description of a GFD-dependent improvement of TAO along with the disappearance of TRAb. This finding supports the hypothesis that gastrointestinal immune dysfunction may have reversible extraintestinal consequences $[2,4]$.

\section{CONFLICTS OF INTEREST}

No potential conflict of interest relevant to this article was reported.

\section{ORCID}

Ilaria Stramazzo https://orcid.org/0000-0001-7870-1729

Camilla Virili https://orcid.org/0000-0002-4973-1950

\section{REFERENCES}

1. Fousekis FS, Katsanos A, Katsanos KH, Christodoulou DK. Ocular manifestations in celiac disease: an overview. Int Ophthalmol 2020;40:1049-54.

2. Lerner A, Shoenfeld Y, Matthias T. Adverse effects of gluten ingestion and advantages of gluten withdrawal in nonceliac autoimmune disease. Nutr Rev 2017;75:1046-58.

3. Ponto KA, Schuppan D, Zwiener I, Binder H, Mirshahi A, Diana $\mathrm{T}$, et al. Thyroid-associated orbitopathy is linked to gastrointestinal autoimmunity. Clin Exp Immunol 2014;178: 57-64.

4. Perros P, Hegedus L, Bartalena L, Marcocci C, Kahaly GJ, Baldeschi L, et al. Graves' orbitopathy as a rare disease in Europe: a European Group on Graves' Orbitopathy (EUGOGO) position statement. Orphanet J Rare Dis 2017;12:72.

5. Eckstein AK, Losch C, Glowacka D, Schott M, Mann K, Esser J, et al. Euthyroid and primarily hypothyroid patients develop milder and significantly more asymmetrical Graves ophthalmopathy. Br J Ophthalmol 2009;93:1052-6. 